\title{
Urbanization and traffic related exposures as risk factors for Schizophrenia
}

\author{
Carsten Bøcker Pedersen* and Preben Bo Mortensen
}

Address: National Centre for Register-based Research, University of Aarhus, Taasingegade 1, 8000 Aarhus C, Denmark

Email: Carsten Bøcker Pedersen* - cbp@ncrr.dk; Preben Bo Mortensen - pbm@ncrr.dk

* Corresponding author

Published: 19 January 2006

BMC Psychiatry 2006, 6:2 doi:10.1 I86/I47|-244X-6-2
Received: 26 May 2005

Accepted: 19 january 2006

This article is available from: http://www.biomedcentral.com/I47I-244X/6/2

(C) 2006 Pedersen and Bo Mortensen; licensee BioMed Central Ltd.

This is an Open Access article distributed under the terms of the Creative Commons Attribution License (http://creativecommons.org/licenses/by/2.0), which permits unrestricted use, distribution, and reproduction in any medium, provided the original work is properly cited.

\begin{abstract}
Background: Urban birth or upbringing increase schizophrenia risk. Though unknown, the causes of these urban-rural differences have been hypothesized to include, e.g., infections, diet, toxic exposures, social class, or an artefact due to selective migration.

Methods: We investigated the hypothesis that traffic related exposures affect schizophrenia risk and that this potential effect is responsible for the urban-rural differences. The geographical distance from place of residence to nearest major road was used as a proxy variable for traffic related exposures. We used a large population-based sample of the Danish population (I.89 million people) including information on all permanent addresses linked with geographical information on all roads and house numbers in Denmark. Schizophrenia in cohort members (10,755 people) was identified by linkage with the Danish Psychiatric Central Register.

Results: The geographical distance from place of residence to nearest major road had a significant effect. The highest risk was found in children living 500-1000 metres from nearest major road (RR $=1.30$ (95\% Confidence Interval: I.17-I.44). However, when we accounted for the degree of urbanization, the geographical distance to nearest major road had no significant effect.

Conclusion: The cause(s) or exposure(s) responsible for the urban-rural differences in schizophrenia risk were closer related to the degree of urbanization than to the geographical distance to nearest major road. Traffic related exposures might thus be less likely explanations for the urban-rural differences in schizophrenia risk.
\end{abstract}

\section{Background}

Although a family history of schizophrenia is the best established risk factor for the disease [1] it may account for a limited proportion of the population occurrence of schizophrenia $[2,3]$. Many studies have identified urbanrural differences in the incidence of schizophrenia (E.g. [2-9]), and a previous study showed that the timing of the urban cause(s) or exposure(s) was from birth to the $15^{\text {th }}$ birthday and that no ages during upbringing were partic- ularly vulnerable to residence in urban areas [4], suggesting that continuous or repeated exposures during upbringing affected schizophrenia risk.

The underlying cause(s) responsible for these differences is currently unknown, but have been hypothesised to include toxic exposures, diet, infections, stress, or an artefact due to selective migration $[10,11]$. However, a Danish study based on a small sample showed an association 
between air pollution from traffic and schizophrenia risk [5], and an American study also based on a small sample showed an association between prenatal exposure to lead and schizophrenia risk [12].

To reduce the number of candidates responsible for the urban-rural differences in schizophrenia risk and to replicate the association between air pollution from traffic and schizophrenia risk in a larger sample, we investigated the hypothesis that traffic related exposures affect schizophrenia risk, and that this potential effect is responsible for the urban-rural differences in schizophrenia risk. As, we had no direct measurements of traffic related exposures for the total Danish Population we used the geographical distance from place of residence to nearest major road as a proxy variable for traffic related exposures.

We utilised a large population-based sample of the Danish population including information on all permanent addresses at which cohort members had lived since 1971 linked with a Geographical Information System containing geographical information on all roads and house numbers in Denmark [13].

We evaluated whether the geographical distance from place of residence to the nearest major road influenced schizophrenia risk and whether this potential effect could explain the effect of the degree of urbanization at place of residence.

\section{Methods}

\section{Study population}

We used data from the Danish Civil Registration System [14] to obtain a large and representative set of data on Danish persons, which for all persons included current and historical information on addresses in Denmark and Greenland, and emigrations and immigrations to and from other countries together with exact dates of changes of residence. All citizens in Denmark are obliged by law to inform the authorities about any change of permanent address within 5 days. Failure to supply this information will result in inability to be on supplementary benefit (e.g., unemployment, sickness or disablement benefits, and educational aid from public funds), to be at day nursery, to be at nursery school, to attend primary and lower secondary school, to avail of free national health care, and to obtain a tax deduction card (required to have paid work), etc. Therefore, it is very unlikely that this mandatory information was not reported. This information was accessible from January 1, 1971. Our study cohort consisted of all persons with known maternal identity who were born in Denmark between January 1, 1956 and December 31, 1983, and who were alive at the 15th birthday (1.89 million persons).

\section{Assessment of schizophrenia and mental illness in a parent or sibling}

Individual information on schizophrenia in cohort members and mental illness in their relatives was obtained by linkage to the Danish Psychiatric Central Register [15]. The Danish Psychiatric Central Register has been computerized since 1969 and contains data on all admissions to Danish psychiatric inpatient facilities. From 1995 on, information on outpatient visits to psychiatric departments was included in the register. There are no private psychiatric departments in Denmark. From 1969 to 1993, the diagnostic system used was the International Classification of Diseases, 8th Revision (ICD-8) [16], and from 1994, the diagnostic system used was the International Classification of Diseases, 10th Revision (ICD-10) [17]. Cohort members were classified with schizophrenia if they had been admitted to a psychiatric hospital or had been in outpatient care with a diagnosis of the disorder (ICD-8 code 295 or ICD-10 code F20). The date of onset was defined as the first day of the first contact (in- or outpatient) with a diagnosis of schizophrenia. Parents and siblings were categorized hierarchically with a history of schizophrenia (ICD-8 code 295 or ICD-10 code F20), schizophrenia-like psychoses (ICD-8 codes 297, 298.39, 301.83 or ICD-10 codes F21-F29), or other mental disorders (Any ICD-8 or ICD-10 diagnosis), respectively, if they had been admitted to a psychiatric hospital or had been in outpatient care with one of these diagnoses.

Assessment of geographical distance to nearest major road The Danish address and road database [13] contains information on the geographical location of all roads in Denmark combined with information on the location of house numbers on each road and with information on size of road classified in six categories: 1) motorways (110 $\mathrm{km} / \mathrm{h}), 2)$ motor roads $(90 \mathrm{~km} / \mathrm{h}), 3)$ primary routes $(80$ $\mathrm{km} / \mathrm{h}$, main roads between cities), 4) secondary routes (80 km/h, main roads within cities), 5) roads 3-6 metres, $6)$ other roads without importance with regard to traffic structure. We used this geographical database, in SAS version 9.1 [18] and the GIS-software MapInfo Professional version $6.0[19]$ to calculate 1) the geographical location of all households in Denmark, and subsequently 2) the geographical distance from each household to the nearest major road. We defined major roads by motorways, motor roads, and primary and secondary roads. The geographical distance to the nearest major road was categorized from 0 to 50 metres, from 50 to 100 metres, from 100 to 250 metres, from 250 to 500 metres, from 500 to 1000 metres, from 1000 to 2000 metres, and above 2000 metres. The completeness of information on the geographical distance to nearest major road increased from 75.5 percent in 1971 to 96.5 percent in 1978 and further to 98.5 percent in 1985 . 


\begin{tabular}{|c|c|c|c|c|c|c|c|c|c|c|c|c|}
\hline \multirow{3}{*}{$\begin{array}{l}\text { Geographical distance to nearest } \\
\text { major road at } 15 \text { th birthday }\end{array}$} & \multicolumn{12}{|c|}{ Degree of urbanization at place of residence at 15 th birthday } \\
\hline & \multicolumn{2}{|c|}{ Capital } & \multicolumn{2}{|c|}{ Capital suburb } & \multicolumn{2}{|c|}{ Provincial city } & \multicolumn{2}{|c|}{ Provincial town } & \multicolumn{2}{|c|}{ Rural area } & \multicolumn{2}{|c|}{ Total } \\
\hline & $\begin{array}{l}\text { No of } \\
\text { People }\end{array}$ & $\begin{array}{c}\text { Col. } \\
\text { percent }\end{array}$ & $\begin{array}{l}\text { No of } \\
\text { People }\end{array}$ & $\begin{array}{c}\text { Col. } \\
\text { percent }\end{array}$ & $\begin{array}{l}\text { No of } \\
\text { People }\end{array}$ & $\begin{array}{c}\text { Col. } \\
\text { percent }\end{array}$ & $\begin{array}{l}\text { No of } \\
\text { People }\end{array}$ & $\begin{array}{c}\text { Col. } \\
\text { percent }\end{array}$ & $\begin{array}{l}\text { No of } \\
\text { People }\end{array}$ & $\begin{array}{c}\text { Col. } \\
\text { percent }\end{array}$ & $\begin{array}{l}\text { No of } \\
\text { People }\end{array}$ & $\begin{array}{l}\text { Col. } \\
\text { percent }\end{array}$ \\
\hline $0-50 \mathrm{~m}$ & 11172 & 8.5 & 13182 & 4.8 & 18793 & 9.8 & 53329 & 10.1 & 101323 & 14.2 & 197799 & 10.7 \\
\hline $50-100 \mathrm{~m}$ & 8382 & 6.3 & 19462 & 7.1 & 20243 & 10.5 & 46135 & 8.8 & 50186 & 7.0 & 144408 & 7.8 \\
\hline $100-250 \mathrm{~m}$ & 27149 & 20.5 & 5785 & 21.0 & 51980 & 27.1 & 129274 & 24.5 & 133021 & 18.6 & 399276 & 21.7 \\
\hline $250-500 \mathrm{~m}$ & 40279 & 30.5 & 72864 & 26.4 & 52090 & 27.2 & 136636 & 25.9 & 133417 & 18.6 & 435286 & 23.6 \\
\hline $500-1000 \mathrm{~m}$ & 36166 & 27.4 & 7879 & 28.6 & 34057 & 17.8 & 99887 & 18.9 & 120778 & 16.9 & 369686 & 20.1 \\
\hline $1000-2000 \mathrm{~m}$ & 8624 & 6.5 & 30059 & 10.9 & 11001 & 5.7 & 42786 & 8.1 & 101972 & 14.3 & 194442 & 10.6 \\
\hline$>2000 \mathrm{~m}$ & 379 & 0.3 & 3284 & 1.2 & 3669 & 1.9 & 19284 & 3.7 & 74375 & 10.4 & 100991 & 5.5 \\
\hline Total & $13215 \mid$ & 100.0 & 275501 & 100.0 & 191833 & 100.0 & 527331 & 100.0 & 715072 & 100.0 & 1841888 & 100.0 \\
\hline
\end{tabular}

A total of $1315 \mathrm{I}$ people $(0.7 \%)$ were not resident in Denmark at the 15 th birthday, and a total of 36976 people $(1.9 \%)$ resident in Denmark at the 15 th birthday had unknown information on the geographical distance to nearest major road at the I5th birthday. The column percent indicates the percentage of people living in a defined degree of urbanization with a specific distance to nearest major road. 
Table 2: Adjusted relative risk of schizophrenia for 1.84 million people born in Denmark 1956-1983 according to place of residence and the distance to nearest major road at the 15th birthday where 10,394 developed schizophrenia 1970-200I.

\begin{tabular}{|c|c|c|c|c|c|}
\hline \multirow{3}{*}{$\begin{array}{l}\text { Geographical distance to nearest } \\
\text { major road at I5th birthday }\end{array}$} & \multicolumn{5}{|c|}{ Relative Risk (95 percent Confidence Interval) * } \\
\hline & \multicolumn{5}{|c|}{ Place of residence at I5th birthday } \\
\hline & Capital & Capital suburb & Provincial city & Provincial town & Rural area \\
\hline $0-50 \mathrm{~m}$ & $2.16(1.76,2.65)$ & $1.42(1.12,1.80)$ & $1.34(1.09,1.65)$ & $1.14(0.97,1.35)$ & $1.10(0.95,1.27)$ \\
\hline $50-100 \mathrm{~m}$ & $2.15(1.71,2.70)$ & $1.53(1.25,1.87)$ & $1.47(1.21,1.80)$ & $1.26(1.07,1.49)$ & $1.04(0.88,1.24)$ \\
\hline $100-250 \mathrm{~m}$ & $2.34(2.00,2.73)$ & $1.51(1.30,1.75)$ & $1.48(1.27,1.72)$ & $1.20(1.05,1.37)$ & $1.02(0.89,1.17)$ \\
\hline $250-500 \mathrm{~m}$ & $2.25(1.95,2.59)$ & $1.47(1.28,1.70)$ & $1.31(1.12,1.54)$ & $1.22(1.06,1.39)$ & $1.04(0.91,1.20)$ \\
\hline $500-1000 \mathrm{~m}$ & $2.14(1.85,2.48)$ & $1.65(1.44,1.89)$ & $1.45(1.21,1.73)$ & $1.13(0.98,1.30)$ & $1.06(0.92,1.22)$ \\
\hline $1000-2000 \mathrm{~m}$ & $1.92(1.49,2.47)$ & $1.63(1.37,1.94)$ & $1.23(0.91,1.65)$ & $1.03(0.86,1.24)$ & $1.05(0.90,1.21)$ \\
\hline$>2000 \mathrm{~m}$ & $0.64(0.09,4.53) \dagger$ & $1.05(0.62,1.80)$ & $1.22(0.75,1.99)$ & $1.23(0.98,1.55)$ & $\mathrm{I} .00$ (ref) \\
\hline
\end{tabular}

There was no interaction between these variables $(p=0.49)$.

*: Estimates of relative risks were adjusted for age and its interaction with gender, calendar year of diagnosis, and mental illness in a parent or sibling.

† This estimate was based on one person with schizophrenia, while all other estimates were based on at least 14 people with schizophrenia.

\section{Assessment of degree of urbanization}

The 275 municipalities in Denmark were classified according to the degree of urbanization [20]: capital, capital suburb, provincial city with more than 100,000 inhabitants, provincial town with more than 10,000 inhabitants, or rural areas. Note that, the measure of the degree of urbanization used in Danish studies (E.g.[2$4,21]$ ) was equal for cohort members living in the same municipality, whereas the geographical distance from place of residence to nearest major road varied among cohort members living in the same municipality.

Additional File 1 shows the degree of urbanization in Denmark along with all major roads in Denmark, and Additional File 2 shows all households in Denmark coloured according to the distance to nearest major road.

\section{Study design}

Using data from the Civil Registration System, for each person in the cohort we calculated the degree of urbanization, and the geographical distance from the place of residence to nearest major road. This information was calculated for each one-year age-point from birth to the 15th birthday. Throughout this paper by place of residence we refer to place of residence at the 15th birthday, and by degree of urbanization we refer to the degree of urbanization at place of residence at the 15th birthday.

Note that, all information was independent of the disease status. A total of 1.89 million persons were followed from their 15th birthday or April 1, 1970 whichever came later, until the date of onset of schizophrenia, the date of death, the date of emigration from Denmark, or December 31, 2001, whichever came first.

\section{Statistical analyses}

The relative risk of schizophrenia was estimated by loglinear Poisson regression [22] with the GENMOD procedure in SAS version 9.1 [18]. All relative risks were adjusted for age and its interaction with gender, calendar year, history of mental illness in a parent or sibling. Age, calendar year, and history of mental illness in siblings were treated as time-dependent variables [23], whereas all other variables were treated as variables independent of time. In order to reduce the risk of residual confounding, age was categorized as, $15,16,17,18,19,20-21,22-23$, $24-25,26-27,28-29,30-34,35-39$, and $>=40$ completed years. Calendar year of diagnosis was categorized in three year age bands from 1970 to 1993 and in one-year age bands thereafter. $\mathrm{P}$ values were based on likelihood ratio tests and 95 percent confidence limits were calculated by Wald's test [23]. The adjusted-score test [24] suggested that the regression models were not subject to overdispersion.

\section{Results}

Among the 1,892,015 people who were included in this study (born in Denmark 1956-1983), 13,151 (0.7 percent) were not resident in Denmark at their $15^{\text {th }}$ birthday and 36,976 (1.9 percent) had unknown information on the geographical distance to nearest major road at the 15th birthday. Among people who lived more than 2000 metres from nearest major road, the lower the degree of urbanization the greater the percentage of people (Table $1)$. The average distance to nearest major road was 440 , 520, 400, 480, and 690 metres for people living in the capital, capital suburb, provincial city, provincial town, and rural area, respectively (results not shown). 
Table 3: Distribution of 10,394 cases of schizophrenia, incidence of schizophrenia, and adjusted relative risks according to the geographical distance to nearest major road at the 15th birthday and the degree of urbanization at the 15th birthday.

\begin{tabular}{|c|c|c|c|c|}
\hline \multirow[t]{2}{*}{ Variable } & \multirow[t]{2}{*}{ No. of cases } & \multirow[t]{2}{*}{ Incidence * } & \multicolumn{2}{|c|}{ Relative Risk (95 percent Confidence Interval) } \\
\hline & & & First Adjustment $\dagger$ & Second Adjustment $\ddagger$ \\
\hline Total & 10,394 & 3.31 & - & - \\
\hline \multicolumn{5}{|c|}{$\begin{array}{l}\text { Geographical distance to nearest major road at the } 15 \text { th } \\
\text { birthday }\end{array}$} \\
\hline $0-50 \mathrm{~m}$ & 1,089 & 3.08 & $1.16(1.04,1.30)$ & $1.05(0.94,1.18)$ \\
\hline $50-100 \mathrm{~m}$ & 846 & 3.37 & $1.25(1.11,1.40)$ & $1.08(0.96,1.21)$ \\
\hline $100-250 \mathrm{~m}$ & 2,308 & 3.38 & $1.25(1.13,1.38)$ & $1.07(0.96,1.18)$ \\
\hline $250-500 \mathrm{~m}$ & 2,560 & 3.47 & $1.27(1.15,1.40)$ & $1.05(0.94,1.16)$ \\
\hline $500-1000 \mathrm{~m}$ & 2,187 & 3.52 & $1.30(1.17,1.44)$ & $1.06(0.96,1.18)$ \\
\hline $1000-2000 \mathrm{~m}$ & 961 & 2.95 & $1.13(1.01,1.27)$ & $1.02(0.91,1.14)$ \\
\hline \multirow[t]{2}{*}{$>2000 \mathrm{~m}$} & 443 & 2.57 & 1.00 (ref) & 1.00 (ref) \\
\hline & & & $(\mathrm{p}<.0000 \mathrm{I})$ & $(p=0.77)$ \\
\hline \multicolumn{5}{|c|}{ Degree of Urbanization at the 15 th birthday } \\
\hline Capital & 1559 & 6.53 & $2.10(1.98,2.24)$ & $2.09(1.96,2.22)$ \\
\hline Capital Suburb & 1947 & 4.07 & $1.48(1.40,1.56)$ & $1.47(1.38,1.56)$ \\
\hline Provincial City & 1154 & 3.49 & $1.34(1.25,1.43)$ & $1.32(1.23,1.42)$ \\
\hline Provincial Town & 2670 & 2.96 & $1.13(1.07,1.19)$ & $1.12(1.06,1.18)$ \\
\hline Rural Area & 3064 & 2.56 & $\begin{array}{c}1.00(\text { ref }) \\
(p<.0000 \mathrm{l})\end{array}$ & $\begin{array}{c}1.00(\text { ref }) \\
(p<.0000 \mathrm{l})\end{array}$ \\
\hline
\end{tabular}

*: Incidence of schizophrenia per 10,000 person years at risk. The incidence measures the number of new cases occurred per time period

† Estimates of relative risks were adjusted for age and its interaction with gender, calendar year of diagnosis, and mental illness in a parent or sibling.

‡ Estimates of relative risk were adjusted for all variables in the first adjustment and for all the variables listed.

A total of 10,755 persons $(7,053$ males and 3,702 females) developed schizophrenia during the 32.6 million person-years at risk. Among those, 10,394 (96.6 percent) cases and 31.4 (96.4 percent) million person-years at risk were resident in Demark and had available information on place of residence and the geographical distance to nearest major road.

\section{Geographical distance to nearest major road at the 15th birthday and the degree of urbanization at the I5th birthday}

The relative risk associated with the distance to nearest major road for each place of residence is shown in Table 2. Those living in the rural area more than 2000 metres from nearest major road were chosen as the reference category. Irrespectively of place of residence, the distance to nearest major road had no influence on the relative risk of schizophrenia, and irrespectively of the distance to nearest major road, the greater the degree of urbanization the greater the risk of schizophrenia. There was no interaction between these variables $(\mathrm{p}=0.49)$.

Table 3 shows the overall effects of place of residence and the distance to nearest major road. The geographical distance to nearest major road $(\mathrm{p}<0.0001)$ and the degree of urbanization ( $\mathrm{p}<0.0001)$ had significant effects (Table 3 , First Adjustment). Cohort members living from 50 to
1,000 metres from nearest major road had the greatest risk of developing schizophrenia, and the greater the degree of urbanization, the greater the risk of developing schizophrenia. Those living in the capital had a 2.10-fold (95 percent CI: $1.98,2.24$ ) increased risk of developing schizophrenia compared to those living in the rural area at the 15th birthday (Table 3, First Adjustment).

When the effect of geographical distance to nearest major road and the degree of urbanization were adjusted mutually (Table 3, Second Adjustment), the effect of geographical distance to nearest major vanished $(\mathrm{p}=0.77)$ while the effect of the degree of urbanization was not modified and remained strongly significant $(\mathrm{p}<0.0001)$. This meant that the degree of urbanization explained the effect of the geographical distance to the nearest major road. Furthermore, there was no interaction between gender and geographical distance to nearest major road (results not shown).

\section{Geographical distance to nearest major road in one-year age points and the degree of urbanization in one-year age points}

Without adjusting for the degree of urbanization, the geographical distance to nearest major road from birth to the 14 th birthday had an effect similar to the effect of geographical distance to nearest major road at the 15 th birth- 
day. Furthermore, when these effects were adjusted for the degree of urbanization at the same age-point, the effect of geographical distance to nearest major road at that agepoint vanished while the effect of the degree of urbanization at that age-point was not modified and remained strongly significant. Therefore, the effect of the geographical distance to the nearest major road during upbringing was explained by the degree of urbanization during upbringing.

Subdividing the results above by road size (motorways, motor roads, primary routes, and secondary routes) gave similar results. Neither the effect of the degree of urbanization, nor the effect of the distance to nearest major road depended significantly on birth year.

\section{Discussion}

We found no evidence that the distance to nearest major road had an impact on the risk of developing schizophrenia when we accounted for place of residence (Tables 2 and 3). Therefore, factors responsible for the urban-rural differences in schizophrenia risk were closer related to the degree of urbanization than to the geographical distance from place of residence to nearest major road. This finding did not support our hypothesis and was somewhat unexpected. Whatever the cause(s) or exposure(s) responsible for the urban-rural differences in schizophrenia risk, we expected the degree of urbanization to be a crude measure of the density of people indicating that the higher the density of people the higher the risk of schizophrenia. The degree of urbanization was calculated using the number of inhabitants in the largest city in each municipality, and therefore all people living in the same municipality were categorised as having the same degree of urbanization irrespectively of the local density of people at their place of residence. However, as the density of people varied within municipalities and might be associated with the geographical distance to road, the geographical distance from place of residence to nearest major road had the potential to contribute with further information on the urban-rural differences in schizophrenia risk. However, our study did not show that.

If short geographical distance to nearest major road was a proxy for traffic related exposures (e.g., CO, Benzene, lead, or noise), our findings suggested that these factors were less likely candidates of explaining the urban-rural differences in schizophrenia risk. In contrast to the current findings, in a previous study [5] based on small numbers (29 people with schizophrenia), we concluded that the level of traffic, $\mathrm{CO}$ and benzene might explain some of the urban-rural differences in schizophrenia risk. Additional studies are needed to pursue this inconsistency.

\section{Strengths and Limitations}

Although many studies identified urban-rural differences in the occurrence of schizophrenia there is no standardized measure of urbanization; some authors defined urbanization by the density of people [25], some as the density of addresses [26-28], some by a large city vs. a small city $[8,9,28,29]$ and other definitions were also used $[6,30]$, and we measured urbanization by the capital area and the number of inhabitants in the largest city in the municipality [2-5,21,31,32]. As long as the cause(s) or exposure(s) responsible for the urban-rural differences in schizophrenia risk are unknown we cannot give guidelines on how the degree of urbanization should be measured.

We used the distance to nearest major road as a proxy for traffic related exposures. However, we had no data documenting whether the distance to nearest major road was a reasonable proxy for traffic related exposures. Such data are currently being collected for 10,000 selected people in the capital area in Denmark. However, although the distance to nearest major road almost certainly was a crude proxy for traffic related exposures and if traffic related exposures were responsible for the urban-rural differences in schizophrenia risk, it was unlikely that the degree of urbanization would be a better proxy for traffic related exposures than the distance to nearest major road. This study suggested that traffic related exposures were not responsible for the urban-rural differences in schizophrenia risk. Previously, Mortensen [10] and Freeman [11] hypothesised that the cause(s) responsible for the urbanrural differences in schizophrenia risk might include toxic exposures, diet, infections, stress, or an artefact due to selective migration.

The strengths of this study were the use of the Danish national registers where we had information on all people living in Denmark, and that all information on exposures was measured independently of the disease.

\section{Concluding remarks}

This is the first study to investigate whether geographical distance from residence to nearest major road influences schizophrenia risk, and it is also the first study to utilise detailed geographical information on the location of each household nation-wide. Methods utilising Geographical Information Systems may prove useful in identifying the underlying unknown causes explaining the urban-rural differences in schizophrenia risk.

\section{Conclusion}

The results of this study do not support the hypothesis that the cause(s) or exposure(s) responsible for the urbanrural differences in schizophrenia risk are closer related to the geographical distance from residence to nearest major 
road than to the degree of urbanization of place of residence. Traffic related exposures may thus be less likely explanations for the urban-rural differences in schizophrenia risk.

\section{Competing interests}

The author(s) declare that they have no competing interests.

\section{Authors' contributions}

CBP designed the study, provided statistical expertise, analysed data and drafted the manuscript. Both authors acquired data on the Danish population used for this study, interpreted the results from the analysis, and revised the manuscript. PBM provided administrative support, and support in obtaining funding. Both authors approved the submitted manuscript.

\section{Additional material}

\section{Additional File 1}

Map of Denmark showing the degree of urbanization and all major roads. Click here for file

[http://www.biomedcentral.com/content/supplementary/1471-

244X-6-2-S1.pdf]

\section{Additional File 2}

Each of the 1.75 million addresses in Denmark coloured according to the calculated geographical distance to nearest major road.

Click here for file

[http://www.biomedcentral.com/content/supplementary/1471-

244X-6-2-S2.pdf]

\section{Acknowledgements}

The study was supported by the Stanley Medical Research Institute. Psychiatric epidemiological research at the National Centre for Register-based Research is in part funded through a collaborative agreement with Centre for Basic Psychiatric Research, Psychiatric Hospital in Aarhus. The Danish address and road database was provided by Kampsax Geoplan, Odense, Denmark.

\section{References}

I. Gottesman II: Schizophrenia genesis. The origins of madness New York, W.H. Freeman and Company; 1991.

2. Mortensen PB, Pedersen CB, Westergaard T, Wohlfahrt J, Ewald H, Mors O, Andersen PK, Melbye M: Effects of family history and place and season of birth on the risk of schizophrenia. $N$ Engl Med 1999, 340:603-608.

3. Pedersen CB, Mortensen PB: Family history, place and season of birth as risk factors for schizophrenia in Denmark: A replication and reanalysis. Br J Psychiatry 200I, 179:46-52.

4. Pedersen CB, Mortensen PB: Evidence of a Dose-response relationship between Urbanicity during Upbringing and Schizophrenia risk. Arch Gen Psychiatry 200I, 58:1039-1046.

5. Pedersen CB, Raaschou-Nielsen O, Hertel O, Mortensen PB: Air pollution from traffic and schizophrenia risk. Schizophr Res 2004, 66:83-85.

6. Haukka J, Suvisaari J, Varilo T, Lonnqvist J: Regional variation in the incidence of schizophrenia in Finland: a study of birth cohorts born from 1950 to 1969. Psychol Med 200I, 31:1045-1053.
7. Suvisaari JM, Haukka JK, Tanskanen AJ, Lonnqvist JK: Decline in the incidence of schizophrenia in Finnish cohorts born from 1954 to 1965. Arch Gen Psychiatry 1999, 56:733-740.

8. Suvisaari JM, Haukka JK, Tanskanen AJ, Lonnqvist JK: Decreasing seasonal variation of births in schizophrenia. Psychol Med 2000, 30:315-324.

9. Lewis G, David A, Andreasson S, Allebeck P: Schizophrenia and city life. Lancet 1992, 340:137- I 40.

10. Mortensen PB: Urban-rural differences in the risk for schizophrenia. Int J Ment Health 2000, 29:10I-IIO.

II. Freeman $\mathrm{H}$ : Schizophrenia and city residence. $\mathrm{Br} J$ Psychiatry Suppl 1994:39-50.

12. Opler MG, Brown AS, Graziano J, Desai M, Zheng W, Schaefer C, Factor-Litvak P, Susser ES: Prenatal lead exposure, delta-aminolevulinic acid, and schizophrenia. Environ Health Perspect 2004, I I 2:548-552.

13. KampSax: Dansk Adresse og Vej database [Danish address and road database] Edited by: KampSax . Odense, Denmark, KampSax; 1998.

14. Malig C: The civil registration system in Denmark. Technical Papers IIVRS 1996, 66:1-6.

15. Munk-Jørgensen P, Mortensen PB: The Danish Psychiatric Central Register. Dan Med Bull 1997, 44:82-84.

16. Organization WH: Manual of the International Classification of Diseases (ICD-8) Geneva, World Health Organization; 1967.

17. Organization WH: The ICD-IO Classification of Mental and Behavioural Disorders. Clinical descriptions and diagnostic guidelines. Geneva, WHO; 1992.

18. Inc. SASI: The GENMOD Procedure. In SASISTAT 9.I User's Guide Cary, NC,, SAS Institute Inc.; 2004:1609-1730.

19. Corporation MI: Maplnfo Professional, Version 6.0 New York, Maplnfo Corporation; 2000.

20. Denmark S: Befolkningen i kommunerne I. januar 1997 [Population in municipalities I January 1997] Copenhagen, Statistics Denmark; 1997.

21. Torrey EF, Mortensen PB, Pedersen CB, Wohlfahrt J, Melbye M: Risk factors and confounders in the geographical clustering of schizophrenia. Schizophr Res 2001, 49:295-299.

22. Breslow NE, Day NE: Statistical Methods in Cancer Research Volume II The Design and Analysis of Cohort Studies IARC Scientific Publications No. 82; 1987.

23. Clayton D, Hills M: Statistical models in epidemiology Oxford, New York, Tokyo, Oxford University Press; 1993.

24. Breslow NE: Generalized linear models: checking assumptions and strengthening conclusions. Statistica Applicata 1996, 8:23-41.

25. Sundquist $K$, Frank G, Sundquist J: Urbanisation and incidence of psychosis and depression: follow-up study of 4.4 million women and men in Sweden. BrJ Psychiatry 2004, 184:293-298.

26. van Os J, Hanssen M, Bijl RV, Vollebergh W: Prevalence of psychotic disorder and community level of psychotic symptoms: an urban-rural comparison. Arch Gen Psychiatry 200 I, 58:663-668.

27. van Os J, Hanssen M, Bak M, Bijl RV, Vollebergh W: Do urbanicity and familial liability coparticipate in causing psychosis? Am J Psychiatry 2003, 160:477-482

28. Marcelis M, Navarro-Mateu F, Murray R, Selten JP, van Os J: Urbanization and psychosis: a study of $1942-1978$ birth cohorts in The Netherlands. Psychol Med 1998, 28:87|-879.

29. Marcelis M, Takei N, van Os J: Urbanization and risk for schizophrenia: does the effect operate before or around the time of illness onset? Psychol Med 1999, 29: I 197-1203.

30. Torrey EF, Bowler AE, Clark K: Urban birth and residence as risk factors for psychoses: an analysis of 1880 data. Schizophr Res 1997, 25:169-176.

31. Pedersen CB, Mortensen PB: Sibship characteristics during upbringing and schizophrenia risk. Am J Epidemiol 2004, 160:652-660.

32. van Os J, Pedersen CB, Mortensen PB: Confirmation of synergy between urbanicity and familial liability in the causation of psychosis. Am J Psychiatry 2004, 161:2312-23 I4.

\section{Pre-publication history}

The pre-publication history for this paper can be accessed here:

http://www.biomedcentral.com/1471-244X/6/2/prepub 